\title{
A NETWORKED LEARNING ENVIRONMENT FOR THE EDUCATION OF AN ARCHITECT
}

\author{
Melis Baloğlu Aşut, Yüksel Demir, Istanbul Technical University, Turkey
}

\begin{abstract}
During a design process, a student of architecture learns how to communicate with various tools, understanding the problem and reflect his/her own solution and how to work together with his/her peers. To be able to examine how a student of architecture learn, communicate and act in a networked environment, this study analyses an architectural theory lesson as a case study in consideration of ACAD (Goodyear \& Carvalho, 2014) framework. An online assistant acts as an observer of the online platform of the course used as a case study, analyses the 14-week course according to ACAD framework. As a conclusion, students can learn collaboratively by articulating and sharing their ideas while they follow their education if they have a chance to frame their own curriculum, and they also continue to share their experience and expertise through discussion and dialog with the help of online communities after they had graduated.
\end{abstract}

\section{Introduction}

The time spent in a classroom or in an architectural studio is not only part of the learning experience of a student of architecture. It is important to develop and orchestrate learning tools to promote learning for the education of an architect both inside and outside of the classroom since the learning process itself creates the learning space each time. That's why, the boundary of a classroom can be measured by the free sharing of ideas inside and outside of the classroom by its learners, discussions, and the free license for the manipulation to the projects created as a part of the lesson. This requires more than a formal environment to learn but a dynamic network. Horizon Report states that "many experts believe that a blending of formal and informal methods of learning can create an environment that fosters experimentation, curiosity, and above all, creativity" (Johnson et al., 2016; p.22). However, the complexity of orchestrating or navigating the diversity of tools to foster curiosity, tasks to foster experimentation and people required to demonstrate knowledgeable action in the networked learning environment. In an educational setting, orchestrating and navigating are mainly done by the teacher but the teacher is not the one and only authority in the networked learning setting. In other words, the teacher is found variously described as "e-moderator" (Salmon, 2004), "facilitator" (Jones \& Steeples, 2002). McConnell et al. (2012) borrowed the terminology "resource person and co-learner" to characterize the teacher's role in the networked learning setting. Teaching is becoming learning by students' active participation. Briefly, we can say that in a networked learning environment: 
- Students and teachers construct the learning process actively so that they are all learners.

- Students are envisaged in connectedness by way of strong and weak ties (Jones et al. 2008) actively supporting each other's learning and mutually fostering a learning network (Goodyear \& Carvalho, 2014). It means that student A learns through student B's comments, questions, and experience.

- In a networked learning environment, it is not so much about the technologies and the types of connections as it is about the promotion of connections for learning: "between one learner and other learners; between learners and tutors; between the learning community and its learning resources" (Goodyear et al., 2010; p.1).

In architectural design education, the learning process can be seen as a result of reflection-inaction during design process described by Schön (1983). Students build their own repertoire consists of ideas and experiences so that when they come face to face with a design problem, they recall something already situated in their repertoire and see the new one as a variation of old which means there is no knowledge independent from our experiences. During a design process, a student of architecture learns how to communicate with various tools, understanding the problem and reflect his/her own solution and how to work together with his/her peers. To be able to examine how a student of architecture learn, communicate and act in a networked environment, this study analyses an architectural theory lesson as a case study in consideration of ACAD (Goodyear \& Carvalho, 2014) framework. In very simple words, according to ACAD framework, design needs to attend to (a) what students are being asked to do, (b) how they should work together to do it, (c) what tools etc. they'll need.

As a conclusion, this study finds potential solutions to support the networked learning environment for the education of an architect. The course named as Architectural Design Theory (ADT) and has been teaching since 2003 by Yüksel Demir and with many participants in the department of Architecture in Istanbul Technical University, Istanbul. There are also other sections who teach the same course with different approaches. The main aim to choose this specific course is related to its dynamic content which is built by its students every semester. Students enrolled the course reflect their own agenda and the course is moderated around students' agenda. ADT is going to be illustrated by ACAD framework to be able to examine:

- What students have been being asked to do and what students should be asked to do?

- How they have been working together to do it and how they should work together to do it?

- What tools, whether digital or analogue, tutors have been using and what tools, whether digital or analogue, they'll need?

- What tools, whether digital or analogue, students have been using and what tools, whether digital or analogue, they'll need?

With such discussions, this work introduces firstly a theoretical background on what is learning in the context of architectural education; secondly, it explains the essence of ACAD framework; thirdly it analyses the case study (ADT) in the light of the ACAD framework and 
reflects on it. As an online observer of the course, I will reflect my observations with the help of ACAD framework. These online observations based on Skype video calls and FB group discussions. They had been systematically collected for 14 weeks from September 2017 till January 2018, on Thursday mornings between 09.30-12.30 (GMT+3). As a brief conclusion:

- Students have been asked to reflect their ideas with different mediums so that they feel comfortable in one way and continue to use this particular way in their group project.

- The community which can be defined as all the students who took the same course, needs to have a course memory to be able to continue to work together according to their changing interests.

- From 2003 to 2019, they have been using different platforms to communicate but none of them are designed for educational purposes as Facebook.

- Students can learn collaboratively by articulating and sharing their ideas while they are in universities, but they also continue to share their experience and expertise through discussion and dialog with the help of online communities after they had graduated.

\section{Learning, Network and Networked Learning}

The focus of networked learning is both learning and the network.

Learning, as Dewey (1900) puts in words by saying that "his activity shall have meaning to himself" (p.23). And, he puts the child/student/learner at the centre of the learning process and emphasizes "reflection in action" which acts as a base for Schön's (1983) work on "reflection in action". Kolb (1984) defines learning as "the process whereby knowledge is created through the transformation of concrete experience. Knowledge results from the combination of grasping and transforming experience" (p.41) Ackermann (2007) adds that knowledge is derived from experience, and actively constructed and reconstructed by subjects in interaction with their worlds. For a designer, knowledge is constructed and reconstructed by herself/himself in interaction with his/her micro world. Both Schön (1983) and Kolb (1984) saw that reflective process is necessary for experiential learning but Schön's ideas of reflection on the problem framing and its relation with the strategies are deeper than Kolb's. During the learning process, designers observing their sketches, seeing them as something else, observing the result and may discover new things. "The student does not just passively take in knowledge, but actively constructs it on the basis of his/her prior knowledge and experiences." (Piaget, 1972; p.26) Students are not passive during the process like they are absorbing all the information given by educators. And also, even designers have something in their minds, when they start to sketch, their aims are reflected in action. The role of the architectural curriculum for design students is to develop an understanding of how they reason in design. It is also based on the creative process of students which is part of their ability of understanding, analysing, questioning, exploring ambiguity and creating relations between different concepts.

Networks have been the subject of research well beyond the impact of the technology alone. The Networked Society is one of the suggested descriptions of the type of social system that is 
emerging in the late 1990s (Castells, 1996). "Networks constitute the new social morphology of our societies, and the diffusion of networking logic substantially modifies the operation and outcomes in processes of production, experience, power, and culture. While the networking form of social organization has existed in other times and spaces, the new information technology paradigm provides the material basis for its expansion through the entire social structure (Castells, 1996; p.468). Learning is epistemically, physically and socially situated and foreground the social nature of knowledge through the notion of networks (Carvalho \& Yeoman, 2018). Networked learning is learning in which communications and information technology (C\&IT) is used to promote connections: between one learner and other learners, between learners and tutors; between a learning community and its learning resources. Such communication can be synchronous and/or asynchronous. It can be text-only or multimedia. It may involve learners who are geographically distributed and/or learners who spend much of their time at a common location. In networked learning (NL) practice, the emphasis on human relations for learning beyond engagement with learning materials using information and communication technologies (ICT) is a significant shift from the prevalent classroom-based lecture which students are used to. Teachers are assumed to take a less prominent position permitting students to experience learning through active participation in cooperative and collaborative activities with others (McConnell et al., 2012).

To sum up, learning is based on experience which means activity centred. Activity is best understood as situated. It unfolds in ways that are shaped, subtly and powerfully, by the physical/digital tools and resources that come to hand, and by the social arrangements obtaining (divisions of labour, roles, etc.) And, the activity cannot be designed. It has emerged. Tasks, the physical/digital setting, and divisions of labour can be designed (Carvalho \& Goodyear, 2014). The next section opens up the framework.

\section{ACAD Framework}

In very simple words, according to ACAD (Activity Centered Analysis and Design) framework (Goodyear \& Carvalho, 2014), design needs to attend to (a) what students are being asked to do, (b) how they should work together to do it, (c) what tools etc. they'll need (with some careful thought about what can be digital, what should be in material form and so on). ACAD can then be seen as a way of helping participants in a learning network converge on methods of representing important aspects of how the network is functioning, such that discussion informed by the representations they construct stands a chance of leading to beneficial action. It can be applied in broad brush ways to create a holistic picture of epistemic, physical and social design components, emergent activity, co-configuration and outcomes (see Figure 1. by Carvalho \& Goodyear, 2014). 


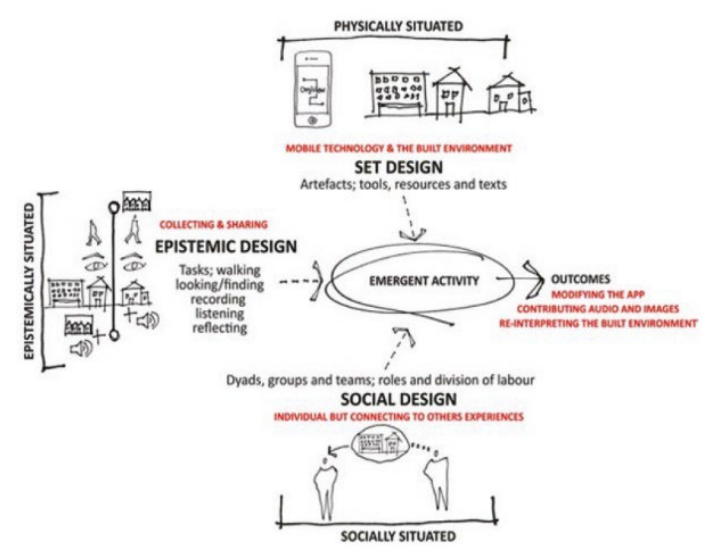

Figure 1. ACAD Framework (Carvalho \& Goodyear, 2014)

The framework acknowledges that design elements are likely to influence people's activity, the activity cannot be entirely predicted. The four structural elements are:

- Set design - the material and/or digital elements that are brought together to compose a learning situation. The setting for networked learning includes places, material and digital tools and artifacts, designed tasks, and associated divisions of labour. These physical architectures need to provide human-to-human, things-to-human, and things-to-things connections to allow activities to emerge. Blackboard, the chairs and tables in a classroom, "built forms" were not especially "brought" to the learning situation by the educational designer, albeit they are still part of the set design.

- Epistemic design - the "plan" for what people will do including the proposed learning tasks, along with their structuring, sequencing and pacing of how information is to be communicated to learners.

- Social design - social arrangements and roles, divisions of labour and who is expected to do what.

- Co-creation and co-configuration activity - relates the above designable components to people's activity, acknowledging that they may rearrange and reconfigure the designed learning situation (Carvalho \& Yeoman, 2018).

\begin{tabular}{|c|c|c|c|}
\hline & Set design & Epistemic design & Social design \\
\hline High-level philosophy & Learning is... & Learning is... & Learning is... \\
\hline $\begin{array}{l}\text { Macro_global Level I } \\
\text { patterns }\end{array}$ & $\begin{array}{l}\text { Buildings and } \\
\text { technology }\end{array}$ & Stakeholder intentions & Organisational forms \\
\hline $\begin{array}{l}\text { Meso-structure Level II } \\
\text { patterns }\end{array}$ & $\begin{array}{l}\text { Allocation and use of } \\
\text { space }\end{array}$ & Curriculum & Community \\
\hline $\begin{array}{l}\text { Micro-details Level III } \\
\text { patterns }\end{array}$ & $\begin{array}{l}\text { Artefacts, tools and } \\
\text { texts }\end{array}$ & $\begin{array}{l}\text { Selection, sequence } \\
\text { and pace }\end{array}$ & $\begin{array}{l}\text { Roles and divisions of } \\
\text { labour }\end{array}$ \\
\hline
\end{tabular}

Figure 2. ACAD wireframe (Carvalho \& Yeoman, 2018)

ACAD framework is also adopted with multiple dimensions as macro, meso and micro. (Carvalho \& Yeoman, 2018) The first three dimensions of design (as per the ACAD framework) are represented from left to right (set, epistemic, and social) and the scale levels across which they operate (macro, meso, and micro) from top to bottom. The shorthand used for the scale levels (macro, meso, micro) is useful, but for a deeper understanding of the 
distinctions between these levels, it is recommended to see Alexander et al.'s (1977) notation: region (macro), shape (meso) and detail (micro) (see in Figure 2.).

\section{Framing a Course: The Case Study, Architectural Design Theory, Istanbul Technical University}

Architectural Design Theory is a theoretical course taught by Yüksel Demir since 2003. The structure of the course makes it unique. The content of the course has been building by its students' agenda in an organized structure for 16 years now. In other words, the curriculum is not designed by a teacher but by students. The tutor acts as a moderator, editor, and learner. I am the online observer of the course for two semesters now. As an online observer of the course, observations are reflected with the help of ACAD framework to be able to see how the course has been processing and how networked learning environment occurs. These online observations based on Skype video calls and FB group discussions. They had been systematically collected for 14 weeks from September 2017 till January 2018, on Thursday mornings between 09.30-12.30 (GMT+3) (see in Figure 3.).

\begin{tabular}{|c|c|c|c|}
\hline & Set Design & Epistemic Design & Social Design \\
\hline High Level Philosophy & $\begin{array}{l}\text { Learning is } \\
\text { physically } \\
\text { situated }\end{array}$ & $\begin{array}{l}\text { Learning is supported } \\
\text { through knowledg-oriented } \\
\text { activity }\end{array}$ & $\begin{array}{l}\text { Learning is } \\
\text { socially } \\
\text { situated }\end{array}$ \\
\hline \multirow[t]{2}{*}{ Macro } & Buildings and technology & Stakeholder intentions & Organisational forms \\
\hline & $\begin{array}{l}\text { The classroom designed to } \\
\text { accom modate max. } 15 \\
\text { students and a tutor, } \\
\text { supported by access to a } \\
\text { closed group on a } \\
\text { social media platform }\end{array}$ & $\begin{array}{l}\text { There is a mix of individual } \\
\text { and group project work } \\
\text { driven by interest and } \\
\text { curiosity. }\end{array}$ & $\begin{array}{l}\text { Each student is responsible } \\
\text { for a project that is of } \\
\text { particular interest to them. } \\
\text { Students enjoy similar } \\
\text { interest-based opportunities. }\end{array}$ \\
\hline \multirow[t]{2}{*}{ Meso } & Allocation and use of space & Curriculum & Comm unity \\
\hline & $\begin{array}{l}\text { The classroom is shared } \\
\text { by } 16 \text { people. The place has } \\
\text { chairs, one board, one desk for } \\
\text { teacher and a projection to } \\
\text { make a presentation. }\end{array}$ & $\begin{array}{l}\text { Each semester, the curriculum } \\
\text { of ADT is designed by } \\
\text { students'. From very } \\
\text { beginning till end, their works } \\
\text { are available online. }\end{array}$ & $\begin{array}{l}\text { The team of } 3 \text { people shares } \\
\text { their responsabilities and roles } \\
\text { while making their final project. } \\
\text { They meet at their spare time } \\
\text { and also they have opportunity } \\
\text { to discuss in class and online. }\end{array}$ \\
\hline \multirow[t]{2}{*}{ Micro } & Artefacts, tools and texts & Selection, sequence and pace & Roles and divisions of labour \\
\hline & $\begin{array}{l}\text { Students who attend ADT, are } \\
\text { also a part of a closed Facebook } \\
\text { group of the course where they } \\
\text { share their response papers, } \\
\text { presentations, GIFs, texts, books, } \\
\text { articles,thoughts, and ideas. } \\
\text { They also encouraged to comment } \\
\text { each others posts. }\end{array}$ & $\begin{array}{l}\text { Students revise their weekly } \\
\text { presentations. At the end, } \\
\text { they formed groups according } \\
\text { their shared interests and write } \\
\text { a final paper on it. }\end{array}$ & $\begin{array}{l}\text { Students are experiencing } \\
\text { difficulty with academ ic writing. } \\
\text { The tutor works with them } \\
\text { during last } 3-4 \text { weeks to revise } \\
\text { their final project. Each week, } \\
\text { the feedback is given both } \\
\text { online and offline. }\end{array}$ \\
\hline
\end{tabular}

Figure 3. ACAD wireframe applied to ADT (adopted from Carvalho \& Yeoman, 2018)

The following subsections reflect the analysis of ADT based on ACAD framework.

\section{Set design in the context of the course Theories of Architectural Design}

At the macro level, the interactions in networked learning environments can, in principle, be through text, voice, graphics, video, shared workspaces or combinations of these forms. However, in mainstream higher education practice, a text is still the dominant medium and much of the time that students and tutors spend in networked learning consists of 
composing, reading and reflecting on electronic texts, such as email messages or entries in text-based computer conferences.

At the meso level, the layout of the classroom is promoting a hierarchical relationship. The tutor has his/her on a place with a big desk compared to students. On the contrary to its layout, the structure of the course makes everybody as learners.

At the micro level, in this case, Facebook supports the constructivist approach to learning through the features as the familiarity of the tool, the interaction of the tool; instructor to student and student to student, connectivity of the tool and opportunity of collaborative learning. There was no length limitation on comment posts. The structure of FB supports good communication in this case since it has the features like tagging people, using hash tags and pinning the important post to the top of the page.

\section{Epistemic design in the context of the course Theories of Architectural Design}

At the macro level, students solved their own problems. If there is an ethical problem, the tutor can also contribute to the discussion.

At the meso level, the tutor acts as a moderator, an editor and a learner. He sometimes linked the ideas of other students from literature or his own background, practice, and expertise to raise the awareness. The content of the course is timeless since it has been building according to students' agendas. This way of orchestrating contribute to learning process and increase curiosity.

At the micro level, from very first day till the end, students started to discuss their interest and they formed a group according to their shared interest. They feel motivated enough to work with their peers and learn how to organize a team according to their expertise.

\section{Social design in the context of the course Theories of Architectural Design}

At macro level, students who took the similar courses rather than ADT, built up similar agendas. That shows institutional power has a visible part on students' agendas.

At meso level, since the students follow their peers' comments on FB, they easily found the one who shared the same interest. They also saw how one had acted until now so that they formed a group according to their values. Monitoring behaviours were set by the students and the tutor.

At micro level, students learn by experiencing by means doing it, seeing the others work, commenting on it and analysing it. Students also learn from the other students' comments, works, and behaviours.

\section{Conclusion}

As it is mentioned in the introduction, ADT is going to be illustrated by ACAD framework to be able to examine: 
1. what students have been being asked to do and what students should be asked to do;

2. how they have been working together to do it and how they should work together to do $i t$

3. what tools, whether digital or analogue, tutors have been using and what tools, whether digital or analogue, they'll need;

4. what tools, whether digital or analogue, students have been using and what tools, whether digital or analogue, they'll need.

- As an answer to (1), students have been asked to reflect their ideas with different mediums so that they feel comfortable in one way and continue to use this particular way in their group project.

- As an answer to (2), the community which can be defined as all the students who took the same course, needs to have a course memory to be able to continue to work together according to their changing interests. In that way, after graduation, students of architecture can remember the theory while heavily practicing.

- As an answer to (3), from 2003 to 2019, they have been using different platforms to communicate but none of them are designed for educational purposes as Facebook. During architectural education, students share their design ideas in various forms. Current learning management systems fail in collecting files, storing them and sharing them. And also, in that tools, there is no room for custom design which can be another topic to study as a user interface design for educational purposes.

- As an answer to (4), students can learn collaboratively by articulating and sharing their ideas while they are in universities, but they also continue to share their experience and expertise through discussion and dialog with the help of online communities after they had graduated. Lifelong learning communities can be constituted with the communities formed during the formal education based on shared interest and continue to grow.

As a final word, the networked learning environment shaped itself. Even there is an online community to support or a tutor who gives all the answers all the time, it is not possible to create a community. The only way to create it, to let people join with their own agenda and form a group according to their shared interest. One can influence the community to hold as one, but if there is a solid structure defined without community's voice, that will be failed. In today's world, curriculums should be designed according learners needs. This is almost impossible because of the crowd of the learners, and everybody is unique, there can be no one who can design a curriculum each time according to changing needs. The proposed way could be a collaborative act of design of the curriculum with the help of the learners and experts together. Tools, both digital and analogue can support to design a dynamic curriculum in a networked environment. ACAD framework helps to see the relations between tools, organization, curriculum and so on.

Further discussions can be done on vicarious learning and see/measure the relevance of the dialog generated by other learners. 


\section{References}

Ackermann, E. K. (2007). Experiences of artifacts: people's appropriations / objects' affordances. In M. Larochelle (Ed.), Ernst von Glasersfeld, Key Works on Radical Constructivism. Sense Publishers.

Alexander, C., Ishikawa, S., Silverstein, M., Jacobson, M., Fiksdahl-King, I.. \& Angel, S. (1977). A pattern language: Towns, buildings, construction. Oxford: Oxford University Press.

Carvalho, L., \& Yeoman, P. (2018). Framing learning entanglement in innovative learning spaces: Connecting theory, design and practice. British Educational Research Journal, 44(6), 1120-1137.

Carvalho, L., \& Goodyear, P. (Eds.) (2014). The architecture of productive learning networks. New York: Routledge.

Castells, M. (1996). The Rise of the Network Society: The Information Age: Economy, Society, and Culture. Oxford: Blackwell Publishers.

Dewey, J. (1900). The School and Society, The Child and the Curriculum. Chicago: University of Chicago Press.

Goodyear, P., \& Carvalho, L. (2014). Framing the analysis of learning network architectures. In L. Carvalho \& P. Goodyear (Eds.), The architecture of productive learning networks. New York: Routledge.

Goodyear, P. (1999). Pedagogical frameworks and action research in open and distance learning. European Journal of Open and Distance Learning. Retrieved from http://www.eurodl.org/?p=archives\&year=1999\&article=35

Jones, C. R., \& Steeples, C. (2002). Perspectives and issues in networked learning. In C. Steeples \& C. R. Jones (Eds.), Networked learning: perspectives and issues (pp. 1-14). London: Springer.

Kolb, D. (1984). Experiential Learning, Experience as the Source of Learning and Development. Englewood Cliffs, NJ: Prentice Hall.

Papert, S. (1980). Mindstorms: Children, computers, and powerful ideas. Basic Books, Inc

Schön, D. (1983). The Reflective Practitioner: How Professionals Think in Action. Basic Books. 